\title{
Synthesis of VIB Group Metals Silicides Dispersed Powders by Electrolysis of Halide-Oxide Melts
}

\author{
Liliia Molotovska $^{1}$, Dmytro Shakhnin $^{1}$, Natalia Uskova $^{1 *}$, Ganna Nikulina $^{2}$, Vladymyr Cherednik $^{2}$, Serge Stukota $^{2}$, \\ Viktor Malyshev ${ }^{1,2}$ \\ 1. Department of Physical Chemistry of Ionic Liquids, V. I. Vernadsky Institute of General and Inorganic Chemistry, National \\ Academy of Sciences of Ukraine, 32/34 Palladina Ave., Kyiv 03142, Ukraine \\ 2. Faculty of Engineering \& Technology, University of Ukraine, 23 Lvivska St., Kyiv 03115, Ukraine
}

\begin{abstract}
Study of electrochemical behavior of chromium (molybdenum, tungsten) and silicon containing melts allowed defining conditions for synthesis of silicides of chromium, molybdenum and tungsten in the form of fine powders by electrolysis of halide-oxide melts. Sequence of stages of electrosynthesis of silicides of molybdenum and tungsten was found as follows: deposition of more electropositive metal (molybdenum or tungsten), deposition of the second component (silicon) on the surface of metal deposited previously, and reaction diffusion of silicon into the deep of the metal-salt "pear" with the formation of silicide phases of different compositions up to the higher silicides. In contrast, during the electrodeposition of chromium silicides, one of the components (chromium) is deposited not in elemental form, but in oxide form, and the other (silicon) acts as a reducing agent for this oxide to form binary compounds. Duration of the synthesis first stage (deposition of refractory metal or of its oxide) depends on the refractory metal compound content in the system and on the cathode current density. Synthesis of silicides is possible due to retention of powders of molybdenum (tungsten) or chromium oxide at the cathode without scaling. Optimal values of concentrations ratio, current density, temperature, and duration of electrosynthesis were found. Phase composition of products were obtained, as well as their chemical and thermal stability, were studied.
\end{abstract}

Key words: Chromium, molybdenum, tungsten, silicides, synthesis, dispersed powders, ionic melts.

\section{Introduction}

Silicon compounds of VI-B group metals belong to an important class of inorganic compounds with a range of valuable properties [1]. Their powders can be converted into construction materials with desired electrophysical, fire resistance, corrosion resistance, and wear resistance properties which make them promising inorganic materials for new developing areas of technology.

Disilicides $\mathrm{MSi}_{2}(\mathrm{M}=\mathrm{Cr}, \mathrm{Mo}, \mathrm{W})$ are the most studied and practically important ones. The most common method for their preparation is synthesis from elementary substances under inert gas atmosphere at temperature 1,273-1,373 K. Other known methods include thermal reduction by

*Corresponding author: Natalia Uskova, Ph.D., research field: high-temperature ionic melts electrochemistry. magnesium and alumininium from oxides at temperature 1,873-2,573 K, chemical vapor deposition of halides, and finally electrolysis of molten salt, which is of the most promising ones [2, 3]. Information regarding obtaining $\mathrm{Cr}$, Mo, and $\mathrm{W}$ silicides by electrolysis of molten salts is scarce. Method for chromium silicides obtaining in silicate (borate)-fluoride melts is described in $[4,5]$, and for molybdenum silicides obtaining in alkali metal fluoride melts $[6,7]$.

Development of practical applications of method of synthesis by electrolysis of melts was hampered by the data lack on electrochemical behavior of compounds used as sources of metal and silicon. According to Malyshev, et al. [8-10], electrochemical behavior was studied of $\mathrm{Na}_{2} \mathrm{MO}_{4}\left(\mathrm{MO}_{3}\right)(\mathrm{M}=\mathrm{Mo}, \mathrm{W})$, and $\mathrm{K}_{2} \mathrm{CrO}_{4}$ in molten $\mathrm{NaCl}-\mathrm{Na}_{3} \mathrm{AlF}_{6}$, and of $\mathrm{SiO}_{2}$ in the same melt [12]. 


\section{Experiments}

For synthesis of $\mathrm{Cr}$, Mo, and $\mathrm{W}$ silicides, their oxygen compounds were used dissolved in $\mathrm{KCl}-\mathrm{KF}$ and $\mathrm{NaCl}-\mathrm{Na}_{3} \mathrm{AlF}_{6}$ mixtures. It enables us to realize large current densities and to use graphite as anode material without risk of anode effect.

To study joint electroreduction of synthesis components, voltammetry method was used. Methodology of current-voltage studies, and also design of electrochemical cell and of electrodes, were similar to those described by Malyshev, et al. [8-11]. Electrode was platinum wire immersed into studied melt.

Deposition of fine powders by electrolysis was carried out in a quartz reactor. Anode was graphite crucible MPG-7, and cathode was tungsten rod. Product was extracted together with the working cathode, mechanically separated from it, and ground.

Silicides are separated by consecutive leaching of salts with hot water and with $10 \%$ solution of $\mathrm{H}_{2} \mathrm{SO}_{4}$ heated up to $50-60{ }^{\circ} \mathrm{C}$. Then, precipitate was washed with distilled water, filtered, and dried to constant weight at $100-105^{\circ} \mathrm{C}$.

Bulk properties were determined by analytical methods, and surface ones were controlled by physical methods: X-ray diffraction, thermogravimetric analysis, and low-temperature adsorption of argon. Phase composition of the powders was determined using DRON-2 device and $\mathrm{Cu} \mathrm{K} \alpha$ radiation, and specific surface area-by BET (brunauer emmett teller) method through low-temperature adsorption of argon. Contents of $\mathrm{Cr}, \mathrm{Mo}$, and $\mathrm{Si}$, and also of main impurities, were found in powders by atomic absorption spectroscopy method using Pye-Unicam spectrometer; tungsten was determined by the gravimetric method.

\section{Results and Discussions}

\subsection{Synthesis of Silicides of Molybdenum and} Tungsten

Preliminary experiments on electrolysis of chromium (molybdenum, tungsten) and silicon containing melts make it possible to generalize findings (Table 1).

In current-voltage curves for chloride-cryolite melts, under joint presence of sodium molybdate and silicon oxide, two waves are observed (Fig. 1a). The first of them is caused by electroreduction of molybdenum oxyfluoride complex, and the second one-by oxyfluoride complex of silicon. Difference between half-wave potentials is $0.8-0.9 \mathrm{~V}$. Sumilar situation is observed in presence of sodium tungstate (Fig. 1b), with the only difference that difference of half-waves potential is $100-150 \mathrm{mV}$ lower. These data confirm that silicides synthesis could be carried out by electrolysis alone in kinetic regime [12].

It causes the following sequence of steps for electrosynthesis of silicides of molybdenum and tungsten: I-deposition of more electropositive metals (molybdenum or tungsten); II-deposition of the second component-silicon-on the surface of Mo or W deposited earlier; III-silicon reaction diffusion into the depth of metal-salt "pear" with formation of silicides phases of different compositions up to higher silicides.

Silicides synthesis process can be described by the electrochemical and chemical Eq. (1) $[9,10,12]$ : at cathode:

$$
\mathrm{MO}_{3} \mathrm{~F}_{2}^{2-}+6 \overline{\mathrm{e}} \rightarrow \mathrm{M}+3 \mathrm{O}^{2-}+2 \mathrm{~F}^{-}
$$

Table 1 Electrochemical systems and melt electrolysis conditions for synthesis of VI-B group metals silicides.

\begin{tabular}{|c|c|c|c|c|c|c|}
\hline Electrolyte & $\begin{array}{l}\text { Refractory metal } \\
\text { containing component }\end{array}$ & $\begin{array}{l}\text { Silicon containing } \\
\text { component }\end{array}$ & $U,(\mathrm{~V})$ & $T,(\mathrm{~K})$ & Cathode product & Literature \\
\hline $\mathrm{Na}_{2} \mathrm{SiF}_{6}\left(\mathrm{~K}_{2} \mathrm{SiF}_{6}\right)$ & $\mathrm{Cr}_{2} \mathrm{O}_{3}, \mathrm{Cr}$ fluorides & $\mathrm{Na}_{2} \mathrm{SiF}_{6}\left(\mathrm{~K}_{2} \mathrm{SiF}_{6}\right)$ & $1.9-2.1$ & 1,273 & $\mathrm{CrSi}_{2}$ & {$[5,6]$} \\
\hline $\mathrm{Li}, \mathrm{Na}, \mathrm{K} / \mathrm{F}$ & Mo Fluorides & $\mathrm{K}_{2} \mathrm{SiF}_{6}$ & $1.9-2.2$ & 1,273 & $\mathrm{MoSi}_{2}$ & {$[7,8]$} \\
\hline $\mathrm{NaCl}-\mathrm{Na}_{3} \mathrm{AlF}_{6}$ & $\mathrm{Na}_{2} \mathrm{MoO}_{4}\left(\mathrm{Na}_{2} \mathrm{WO}_{4}\right)$ & $\mathrm{SiO}_{2}$ & $1.8-2.2$ & 1,173 & $\begin{array}{l}\mathrm{Mo}_{3} \mathrm{Si}_{5}, \mathrm{MoSi}_{2}, \\
\mathrm{~W}_{3} \mathrm{Si}_{5}, \mathrm{WSi}_{2}\end{array}$ & {$[9,12]$} \\
\hline $\mathrm{NaCl}-\mathrm{Na}_{3} \mathrm{AlF}_{6}$ & $\mathrm{~K}_{2} \mathrm{CrO}_{4}$ & $\mathrm{SiO}_{2}$ & $2.5-3$ & 1,173 & $\mathrm{Cr}_{3} \mathrm{Si}, \mathrm{CrSi}, \mathrm{Al}$ compd. & {$[10,12]$} \\
\hline $\mathrm{KCl}-\mathrm{KF}$ & $\mathrm{K}_{2} \mathrm{CrO}_{4}$ & $\mathrm{~K}_{2} \mathrm{SiF}_{6}\left(\mathrm{SiO}_{2}\right)$ & $3.0-4.0$ & 1,173 & $\mathrm{Cr}_{3} \mathrm{Si}, \mathrm{CrSi}_{2}$ & {$[11,12]$} \\
\hline
\end{tabular}




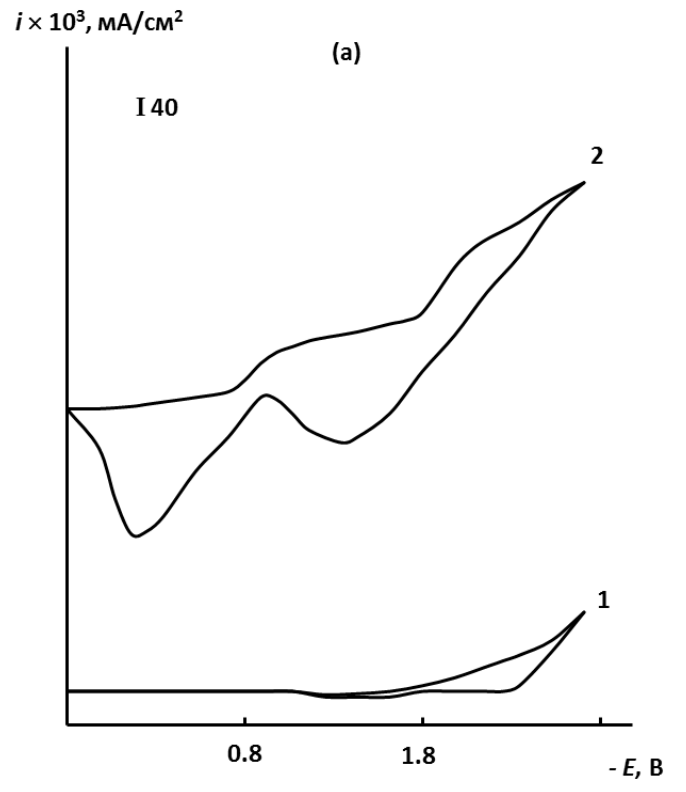

$i \times 10^{3}, \mathrm{MA} / \mathrm{cm}^{2}$

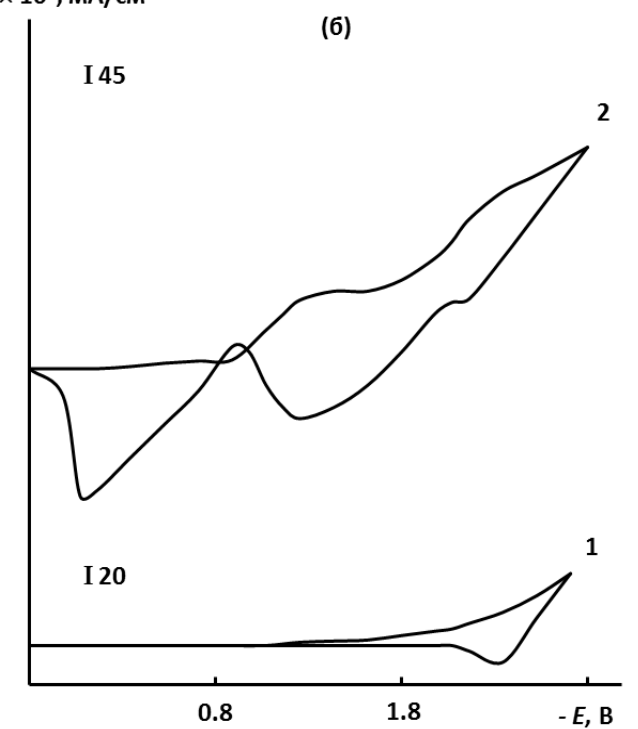

Fig. 1 Voltammograms of melt NaCl-Na $\mathrm{AlF}_{6}(50 / 50$ wt.\%) (1) containing $2.3 \times 10^{-5} \mathrm{~mol} / \mathrm{cm}^{3} \mathrm{Na}_{2} \mathrm{MoO}_{4}$ and $14.0 \times 10^{-5}$ $\mathrm{mol} / \mathrm{cm}^{3} \mathrm{SiO}_{2}$ (a) and $2.3 \times 10^{-5} \mathrm{~mol} / \mathrm{cm}^{3} \mathrm{Na}_{2} \mathrm{WO}_{4}$ and $24.0 \times$ $10^{-5} \mathrm{~mol} / \mathrm{cm}^{3} \quad \mathrm{SiO}_{2}$; (b) Polarization rate $0.1 \mathrm{~V} / \mathrm{s}$; electrode-platinum-oxygen, $T=1,173 \mathrm{~K}$.

$$
\begin{gathered}
\mathrm{SiO}_{2} \mathrm{~F}_{2}^{2-}+4 \overline{\mathrm{e}} \rightarrow \mathrm{Si}+2 \mathrm{O}^{2-}+2 \mathrm{~F}^{-} \\
\mathrm{M}+\mathrm{zSi}=\mathrm{MSi}_{\mathrm{z}}
\end{gathered}
$$

at anode:

$$
2 \mathrm{O}^{2-}-4 \overline{\mathrm{e}}+\mathrm{C} \rightarrow \mathrm{CO}_{2}
$$

Duration of the first stage of synthesis depends on amount of refractory metal in system and on cathode current density. To obtain molybdenum or tungsten in form of fine powder, current density should be the maximum possible one.

The second stage begins with exhausting of electropositive component. Synthesis of silicides can be carried out only under conditions that molybdenum or tungsten powders deposit at cathode surface in form of metal-salt "pear" of such size and shape which allow it to be held firmly at the cathode without breaking. In case of the metal (W or Mo) powders falling out to the electrolyzer bottom, synthesis components are not in contact with each other, and silicides synthesis does not occur.

Temperature of electrochemical synthesis of molybdenum and tungsten silicides is $850-900{ }^{\circ} \mathrm{C}$. Gain in energy of interaction compared with known synthesis processes is provided by interaction of deposited at cathode fine powders of Mo (W) and silicon at atomic level.

Optimization of process of electrochemical synthesis of silicides of molybdenum or tungsten is reduced to determination of concentration ratio, current density and temperature values, and also of process duration.

Choice of concentration ratios of components was guided by the following considerations. According to Grjotheim, et al. [13], silicon dioxide has a limited solubility in molten cryolite $(8.82 \mathrm{wt} . \%)$ at $1,010{ }^{\circ} \mathrm{C}$. Addition of sodium chloride to cryolite results in lower mixture melting temperature and higher solubility of $\mathrm{SiO}_{2}$. In eutectic melt $\left(737{ }^{\circ} \mathrm{C}\right.$; $68.5 \mathrm{wt} . \% \mathrm{NaCl}$ and 31.5wt.\% $\mathrm{Na}_{3} \mathrm{AlF}_{6}$ ), its solubility is about 1.0wt.\%. Maximal content of cryolite in binary system $\mathrm{NaCl}-\mathrm{Na}_{3} \mathrm{AlF}_{6}$ which allow to carry out electrolysis at $900{ }^{\circ} \mathrm{C}$ is $70 \mathrm{wt} . \%$ with the $\mathrm{SiO}_{2}$ solubility in melt of such composition 2.0wt.\%. Concentration of sodium molybdate (tungstate) is determined by value of $\mathrm{SiO}_{2}$ solubility which provides for stoichiometric composition silicides obtaining. Choosing the concentration of the refractory metal oxysalt, one should also take into account the first stage of electrochemical synthesis. The first stage is formation of metal-salt "pear", and 
process of deposition of silicon starts after salt exhaustion. Salt concentration in melt (with $i_{k}=$ const) defines duration of metal deposition at cathode and size of metal-salt "pear". For complete siliconizing of deposited molybdenum or tungsten, content of $\mathrm{Na}_{2} \mathrm{MO}_{4}$ in melt should not exceed $2 \mathrm{wt} . \%$.

Essential role in electrochemical synthesis of silicides of Mo and $\mathrm{W}$ is played by temperature and current density values. Lowering the temperature below $850{ }^{\circ} \mathrm{C}$ does not ensure completeness of interaction of $\mathrm{Mo}(\mathrm{W})$ and $\mathrm{Si}$, and temperature rise above $950{ }^{\circ} \mathrm{C}$ reduce stability of metal-salt "pear" due to which silicides are not formed. With optimal melt composition, pure products were obtained with current density $0.5-1.2 \mathrm{~A} / \mathrm{cm}^{2}$ for $\mathrm{MoSi}_{2}$ and $0.5-1.5 \mathrm{~A} / \mathrm{cm}^{2}$ for $\mathrm{WSi}_{2}$. With $\mathrm{i}_{\mathrm{k}}<0.5 \mathrm{~A} / \mathrm{cm}^{2}$, obtained product is contaminated with Mo or W. Within the range of current density $0.5-1.5 \mathrm{~A} / \mathrm{cm}^{2}$, with current density increase, dispersity of Mo and W silicides increases.

During electrochemical synthesis of silicides of Mo and $\mathrm{W}$, as well as during direct interaction of simple substances, main process is silicon diffusion through metal layer. In such a case, metal is weakly involved in diffusion, and higher silicides are formed in such a system from lower ones. Therefore, obtained products composition is influenced significantly by process duration. Thus, melt having a composition wt.\%: NaCl-49; $\mathrm{Na}_{3} \mathrm{AlF}_{6}-49.0 ; \mathrm{Na}_{2} \mathrm{MoO}_{4}-1.0 ; \mathrm{SiO}_{2}-1.0$, at $900{ }^{\circ} \mathrm{C}$ and with current density $1.0 \mathrm{~A} / \mathrm{cm}^{2}$, depending on electrolysis duration, different products are produced:

\begin{tabular}{llllll}
\hline $\begin{array}{l}\text { Duration, } \\
\text { (min): }\end{array}$ & 10 & 20 & 30 & 45 & 60 \\
\hline $\begin{array}{l}\text { Phase } \\
\text { composition: }\end{array}$ & $\mathrm{Mo}$ & $\begin{array}{l}\mathrm{Mo}_{2} \\
\mathrm{Mo}_{5} \mathrm{Si}_{3}\end{array}$ & $\begin{array}{l}\mathrm{Mo}_{5} \mathrm{Si}_{3}, \\
\mathrm{MoSi}_{2}\end{array}$ & $\mathrm{MoSi}_{2}$ & $\begin{array}{l}\mathrm{MoSi}_{2}, \\
\mathrm{Si}\end{array}$ \\
\hline
\end{tabular}

Similar dependence of phase composition on electrolysis duration is observed in $\mathrm{NaCl}-\mathrm{Na}_{3} \mathrm{AlF}_{6}-\mathrm{Na}_{2} \mathrm{WO}_{4}-\mathrm{SiO}_{2}$ system. Thus, optimal electrolysis duration is $45-50 \mathrm{~min}$.

Washed free of salts and silicon and dried silicides of Mo and W are fine powders with particle size of 0.1-5 $\mu \mathrm{m}$. The main parameters characterizing experimental samples are presence of free silicon and impurities content, as well as specific surface area of samples.

According to X-ray analysis data, in some cases products contained free silicon which was removed by treatment with hot sodium hydroxide solution. Degree of free silicon removal was controlled by X-ray diffraction data (Fig. 2).

Washed free from silicon molybdenum and tungsten disilicides have content of impurities ( $\mathrm{Si}, \mathrm{Na}$, Al) at level of hundredths of a percent. Specific surface of $\mathrm{Mo}_{2} \mathrm{Si}$ and $\mathrm{WSi}_{2}$ is $6-15 \mathrm{~m}^{2} / \mathrm{g}$.

It is known that Group VI silicides are highly chemically stable compounds, and $\mathrm{MoSi}_{2}$ is the most oxidation-resistant one among oxygen-free compounds. Temperature of beginning of active oxidation of $\mathrm{MoSi}_{2}$ is $1,600{ }^{\circ} \mathrm{C}$, and of $\mathrm{WSi}_{2}-1,400{ }^{\circ} \mathrm{C}$ [14]. However, fine powders of $\mathrm{MoSi}_{2}$ are oxidized in air at about $370{ }^{\circ} \mathrm{C}$ (Fig. 3) to form $\mathrm{MoO}_{2}, \mathrm{MoO}_{3}, \mathrm{SiO}_{2}$.

\subsection{Electrochemical Synthesis of Chromium Silicide}

Initially, high-temperature electrochemical synthesis of chromium silicide is carried out from a mixture of molten $\mathrm{NaCl}-\mathrm{Na}_{3} \mathrm{AlF}_{6}-\mathrm{K}_{2} \mathrm{CrO}_{4}-\mathrm{SiO}_{2}$. Voltammetric

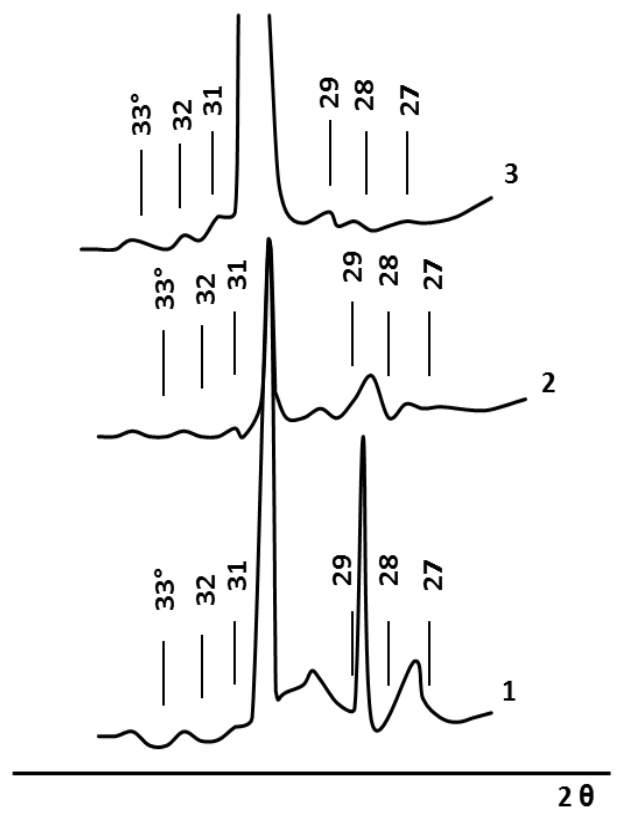

Fig. 2 Diffractograms of powders of $\mathrm{Mo}_{2} \mathrm{Si}$ : 1-initial; 2 , 3-after treatment with $\mathrm{NaOH}$ solution for 20 min and 120 min, respectively. 


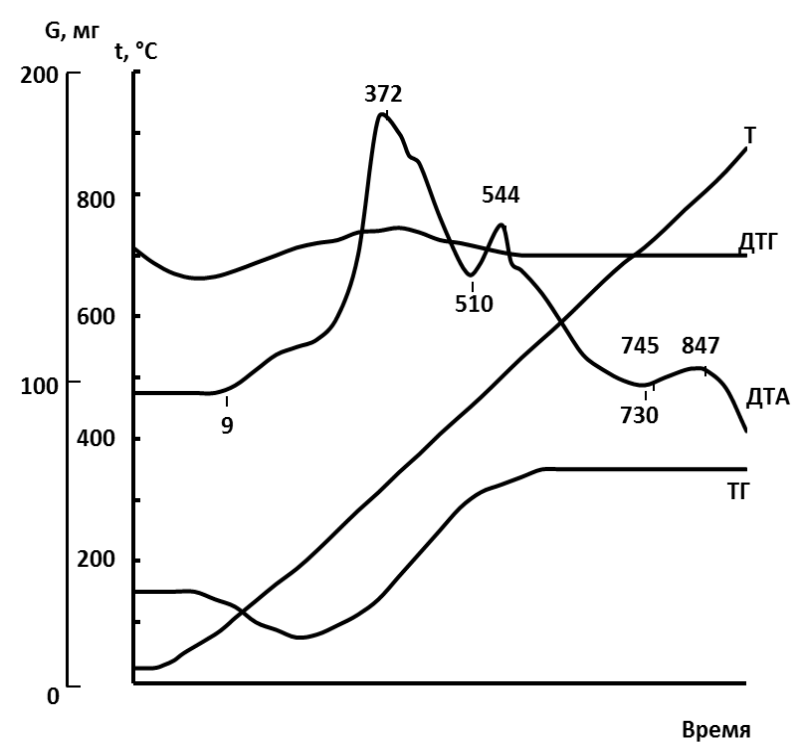

Fig. 3 Derivatograms heating fine powder of $\mathrm{MoSi}_{2}$ in air.

curves show reduction waves of oxyfluoride complexes of $\mathrm{Cr}$ and $\mathrm{Si}$ at significantly different potentials, -(0.7-0.9) $\mathrm{V}$ and -(1.6-1.9) $\mathrm{V}$, respectively. Depending on composition and electrolysis parameters, $\mathrm{Cr}_{2} \mathrm{O}_{3}$, higher silicide $\mathrm{CrSi}_{2}$, and silicide $\mathrm{Cr}_{3} \mathrm{Si}$ phases were obtained as a mixture with aluminum compounds.

To optimize synthesis conditions for chromium silicides containing no aluminum compounds, electrochemical synthesis was carried out in $\mathrm{KCl}-\mathrm{KF}_{-} \mathrm{K}_{2} \mathrm{SiF}_{6^{-}}$ $\mathrm{K}_{2} \mathrm{CrO}_{4}$ system. The resulting current-voltage dependences (Fig. 4) show reduction waves for oxyfluoride complexes of $\mathrm{Cr}$ and $\mathrm{Si}$ at significantly different potentials.

Depending on electrolyte composition and electrolysis parameters, both individual phases $\mathrm{Cr}_{2} \mathrm{O}_{3}, \mathrm{Cr}_{3} \mathrm{Si}$, and $\mathrm{CrSi}_{2}$, and also mixtures of these phases with low silicon content were obtained (Table 2). Choosing concentrations of $\mathrm{CrO}_{4}{ }^{2-}$ and $\mathrm{SiO}_{2}\left(\mathrm{~K}_{2} \mathrm{SiF}_{6}\right)$, it should be taken into account that, at the first stage of electrolysis, $\mathrm{Cr}_{2} \mathrm{O}_{3}$-salt "pear" is formed which starts to become siliconized during exhaustion of the refractory metal. Unlike high-temperature electrochemical synthesis of silicides of molybdenum and tungsten, during this synthesis, one of components are not deposited in elementary form but rather in oxide form,

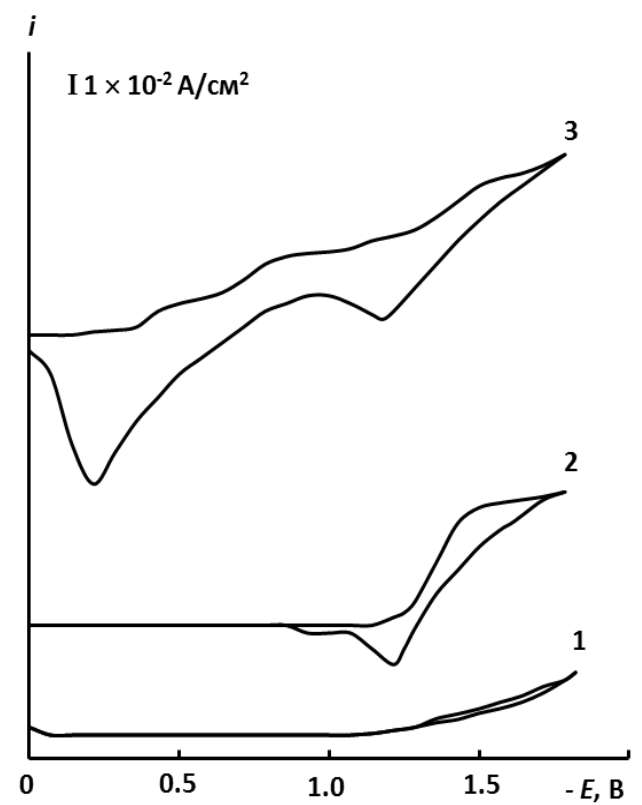

Fig. 4 Voltammograms of molten KCl-KF(1:1)-K $\mathrm{K}_{2} \mathrm{SiF}_{6}-$ $\mathrm{K}_{2} \mathrm{CrO}_{4}$ system. The concentration of $\mathrm{K}_{2} \mathrm{SiF}_{6}$ is: $0,2 \times 10^{-5}$ $\mathrm{mol} / \mathrm{cm}^{3}$ and $2 \times 10^{-5} \mathrm{~mol} / \mathrm{cm}^{3}$, respectively ( curve 1 to 3 ); The concentration of $\mathrm{K}_{2} \mathrm{CrO}_{4}$ is: 0,0 and $5 \times 10^{-5} \mathrm{~mol} / \mathrm{cm}^{3}$, respectively ( curve 1 to 3 ). $T=1,173 \mathrm{~K}$, cathode material-platinum, polarization rate-0.1 V/s.

Table 2 Phase composition of electrolysis products of system KCl-KF (25wt.\%)- $\mathrm{K}_{2} \mathrm{SiF}_{6}(1 \mathrm{wt} . \%)-\mathrm{SiO}_{2}-\mathrm{K}_{2} \mathrm{CrO}_{4}(\mathrm{t}=$ $900{ }^{\circ} \mathrm{C}, \mathrm{U}=3-4 \mathrm{~V}$ )

\begin{tabular}{llllll}
\hline $\mathrm{K}_{2} \mathrm{CrO}_{4}$, & \multicolumn{5}{l}{ The duration of electrolysis (min) } \\
\cline { 2 - 5 } (wt.\%) & 5 & 10 & 15 & 30 & 60 \\
\hline 0.5 & $\mathrm{Cr}_{2} \mathrm{O}_{3}$ & $\mathrm{Cr}_{3} \mathrm{Si} ; \mathrm{Si}$ & $\begin{array}{l}\mathrm{Cr}_{3} \mathrm{Si}_{2} ; \\
\mathrm{CrSi}_{2}\end{array}$ & $\mathrm{CrSi}_{2}$ & $\mathrm{CrSi}_{2} ; \mathrm{Si}$ \\
\hline 1.0 & $\mathrm{Cr}_{2} \mathrm{O}_{3}$ & $\mathrm{Cr}_{3} \mathrm{Si} ; \mathrm{Si}$ & $\mathrm{Cr}_{3} \mathrm{Si} ; \mathrm{Si}$ & $\begin{array}{l}\mathrm{Cr}_{3} \mathrm{Si} ; \\
\mathrm{CrSi}_{2}\end{array}$ & $\mathrm{CrSi}_{2} ; \mathrm{Si}$ \\
\hline
\end{tabular}

and the other act as a reducing agent of the mentioned oxide to form binary compounds.

\section{Conclusions}

Thus, during electrolysis of chromium (molybdenum, tungsten) and silicon containing melts, high temperature electrochemical synthesis of powders of silicides of chromium, molybdenum, and tungsten was implemented.

\section{References}

[1] Vinokourov, L., and Ivanov, V. 1991. "Silicides." Moscow: Nauka.

[2] Lovering, D. 1982. "Molten Salt Technology." New York: 
Plenum Press.

[3] Malyshev, V. 2004. "High-temperature Electrochemistry and Electrodeposition of IV-VIA Groups Metals and their Compounds in Ionic Melts." Kyiv: University Ukraine.

[4] Dodero, M. 1950. "High-temperature Electrochemical Synthesis of Molybdenum and Tungsten Silicides in Ionic Melts." Bul. Soc. Chim. Fr. 17: 545-6.

[5] Hagenmuller, P. 1976. Preparative Methods in Solid State Chemistry. Moscow: Mir.

[6] Stern, K. 1987. Electrodeposition of refractory metal silicides. US Patent 4,662,998, filed December 12, 1985, and issued May 5, 1987.

[7] Stern, K., and Wiliams, C. 1986. "Electrodeposition of Tantalum Silicide Coatings from Molten Salts." $J$. Electrochem. Soc. 133: 2157-60.

[8] Malyshev, V., Gab, A., and Gaune, E. M. 2008. "Molybdenum Electrometallurgical Processes in Ionic Melts." Materials and Manufacturing Processes. 23: 748-51.

[9] Malyshev, V., and Gab, A. 2011. "High-temperature
Galvanic Coatings of Molybdenum, Tungsten, and Their Carbides from Ionic Melts." Physical Chemistry of Surfaces and Protection of Materials. 47: 525-33.

[10] Malyshev, V. 2011. "Chemical and Electrode Reactions Involving Chromium Compounds Underlying its Electrodeposition from Ionic Melts." Izv. VUZov. Non-ferrous Metallurgy 6: 12-21.

[11] Molotovska, L., Uskova, N., and Malyshev, V. 2011. "Electroreduction of Silicon Ions against the Background of the Melt NaCl-Na $\mathrm{AlF}_{6}$." Questions of Chemistry and Chemical Technology 4 (2): 75-6.

[12] Malyshev, V., Kushkov, H., and Shapoval, V. 2002. "High-Temperature Electrochemical Synthesis of Carbides, Silicides, and Borides of VI-A Group Metals in Ionic Melts." J. Applied Electrochemistry 32: 573-9.

[13] Grjotheim, K., Krohn, C., and Malinovsky, M. 1977. Aluminium Electrolysis. Dusseldorf: Aluminium-Verlag Gmbh.

[14] Samsonov, G. 1959. Silicides and their Industrial Applications. Kiev: Publishing House of the USSR Academy of Sciences. 